\title{
UM OLHAR RIZOMÁTICO SOBRE O CONCEITO DE LETRAMENTO DIGITAL
}

\section{A RHIZOMATIC OUTLOOK ON THE DIGITAL LITERACY CONCEPT}

\section{Flavia Girardo Botelho Borges*}

\section{RESUMO}

Este artigo tem por objetivo apresentar uma análise das principais concepções de letramento digital (XAVIER, 2007, 2011, LANKSHEAR; KNOBEL, 2008, SOARES, 2003), para, em seguida, propor um novo olhar para o fenômeno a partir da perspectiva do rizoma (DELEUZE; GUATTARI, 1995). O rizoma incorpora os princípios de conectividade, heterogeneidade, multiplicidade, ruptura, cartografia e decalque, que marcam a permanência e transitoriedade no entendimento do letramento digital e delineiam a complexidade do fenômeno. Para tanto, o artigo está organizado em seis seções, que recobrem a introdução e a primeira parte, que desenha o momento sócio-histórico do fenômeno abordado. Em seguida, a segunda e terceira partes apresentam o mapa conceitual do letramento digital tanto internacional quanto nacionalmente, para construir, nesta esteira, o terreno rizomático do conceito que propomos, na quarta parte. Por fim, a conclusão, na qual tecemos as considerações finais sobre este trabalho epistemológico, esperando contribuir para a discussão e estudos sobre o letramento digital na contemporaneidade.

Palavras-chave: Linguística Aplicada; Letramento digitali Rizoma.

\section{ABSTRACT}

This paper presents an analysis on the primary concepts on digital literacy (XAVIER, 2007, 2011, LANKSHEAR; KNOBEL, 2008, SOARES, 2002), in order to, afterwards, propose a new outlook on the phenomenon from the rhizome standpoint (DELEUZE; GUATTARI, 1995). Rhizome encompass principles of connection, heterogeneity, multiplicity, rupture, cartography and decalcomania, which show the permanence and transience present in digital literacy understanding while tracing the phenomenon complexity. Thus, six sections structure this paper, starting with an introduction, the first section depicting the sociohistorical context of the presented phenomenon. Then, the second and third sections trace the conceptual map for digital literacy, both worldwide and Brazilian, to build upon the rhizomatic terrain for the concept proposed in the fourth section. Lastly, a conclusion wherein, hoping to promote further debate and studies on contemporary digital literacy, epistemological study weaves its conclusions.

Keywords: Applied Linguistics; Digital literacy; Rhizome.

\footnotetext{
* Universidade Federal de Mato Grosso, Cuiabá (MT), Brasil. flavia2b@gmail.com http://dx.doi.org/10.1590/010318134874175011
} 


\section{INTRODUÇÃO}

O momento sócio-histórico que atravessa este artigo e suas reflexões, por ora chamado de pós-modernidade (LYOTARD, 2010), gera incertezas e possibilidades sobre as práticas de letramento. Incertezas porque, no presente, há indícios de que as práticas de letramento convencionais comecem a se tornar insuficientes para que o sujeito esteja efetivamente inserido na sociedade. E possibilidades, já que novos letramentos (digital/multiletramentos) estão sendo constantemente construídos por e para os sujeitos, estabelecendo uma nova e multifacetada área de estudos dentro da Linguística Aplicada, com contribuições de outras áreas como a Psicologia, a Neurociência, a Educação e a Ciência da Computação.

Tomamos como consenso o fato de que vivemos em uma sociedade altamente letrada, centrada na cultura grafocêntrica, rodeada de livros, papéis, documentos impressos ou escritos à mão ou postados em redes sociais, panfletos, propagandas em paredes, pichações, e tantas outras manifestações das possibilidades da escrita. Esses, dentre outros inúmeros, são exemplos do que Soares (2002, p. 145) entende por letramento, "estado ou condição de indivíduos ou de grupos sociais de sociedades letradas que exercem efetivamente as práticas sociais de leitura e escrita, participam competentemente de eventos de letramento".

A perspectiva do letramento incorpora à vida social dos sujeitos a necessidade de dominar as práticas de leitura e escrita com o risco de, não as dominando, encontrar em dificuldade de identificação e integração àquela comunidade, sociedade. Goody (2006, p. 17) aponta que o domínio da linguagem, da língua, atua na vida do indivíduo como "a organização homeostática do corpo humano, por meio da qual ele tenta manter sua condição de vida presente", sendo impossível permanecer num grupo sem dominar os usos de linguagem pertencentes ao mesmo.

Na mesma perspectiva, Bazerman (2007, p. 21) afirma que "o letramento é parte constitutiva de uma matriz de formações culturais e sociais complexas da sociedade moderna com a qual respondemos a instituições, crenças, grupos de pessoas localizados longe de nossa vida diária" e que nos tornaria parte dessa sociedade. Concordamos com Buzato, quando este afirma que adquirir um certo letramento

É participar de um conjunto de práticas sociais nas quais significados e sentidos de certos conteúdos codificados culturalmente (tradicionalmente, mas não exclusivamente, textos escritos) são gerados, disputados, negociados e transformados. (BUZATO, 2010, p. 53) 
Essa aquisição tem sido realizada pelas atividades da leitura e da escrita, na escola, na mídia e na sociedade. Todavia, na sociedade pós-moderna, vivemos uma época integrada à tecnologia e, para estar e sentir-se inserido nas práticas de leitura e escrita atuais, é preciso dominar mais que a leitura e a escrita convencionais, é preciso letrar-se digitalmente.

O cenário atual é resultado da mudança de paradigma exercida pela cibercultura, definida, segundo Lemos (2003, p. 11), como "a forma sociocultural que emerge da relação simbiótica entre a sociedade, a cultura e as novas tecnologias de base microeletrônica que surgiram com a convergência das telecomunicações com a informática na década de $70^{\prime \prime}$ e que modificou as formas de agir, pensar, comunicar-se e se relacionar.

A abrangência da cibercultura na vida cotidiana é inegável, de forma que hoje há a necessidade de outro letramento, além daquele originalmente ofertado pela escola, o letramento digital, que precisa ser investigado e explorado. Nesse ínterim, Xavier explica que o letramento digital

Considera a necessidade dos indivíduos dominarem um conjunto de informações e habilidades mentais que devem ser trabalhadas com urgência pelas instituições de ensino, a fim de capacitar o mais rápido possível os alunos a viverem como verdadeiros cidadãos neste novo milênio cada vez mais cercado por máquinas eletrônicas e digitais. (XAVIER, 2007, p. 133)

Nesse sentido, os estudiosos holandeses Veen e Vrakking (2009) defendem que a aprendizagem dos sujeitos da era digital se realiza de maneira muito diferente daquela conhecida anteriormente. Para esses autores "a geração da rede difere de qualquer outra do passado porque cresceu em uma era digital" (VEEN, VRAKKING, 2009, p. 29).

Como prática cotidiana da cultura digital, nós podemos desenvolver, a partir dos recursos do mundo digital, habilidades linguístico-cognitivas, assim denominadas já que para sua realização necessitam ativar a linguagem e, consequentemente, a cognição. São processos como a atenção, a memória, a percepção, a realização de inferência, entre outras, necessários para o acesso a páginas da rede, leitura de hipertexto, entendimento do funcionamento de links, participação em jogos digitais, acesso a sites, participação em redes sociais, entre outras atividades com as ferramentas digitais.

Em relação aos novos saberes proporcionados pela cibercultura, Lévy aponta que

O ciberespaço suporta tecnologias intelectuais que amplificam, exteriorizam e modificam numerosas funções cognitivas humanas: memória (banco de dados, hiperdocumentos, 
arquivos digitais de todos os tipos), imaginação (simulações), percepção (sensores digitais, telepresença, realidades virtuais), raciocínios (inteligência artificial, modelização de fenômenos complexos). (LÉVY, 1999, p. 157)

Nossa exposição às tecnologias intelectuais viabilizam a vivência na e da cibercultura, ou seja, o contato e a prática frequentes de ações que demandam o uso de diferentes linguagens para consignar momentos de interação mediada por computador estão nos impulsionando a desenvolver estratégias de natureza linguístico-cognitivas, as quais, por ora, estamos chamando de letramento digital. Sobre essa questão, Lévy (1999, p. 157) explica que as atividades digitais "favorecem modos inovadores de acesso à informação e novos estilos de raciocínio e conhecimento, ainda a possibilidade compartilhamento entre numerosos indivíduos".

$\mathrm{Na}$ mesma direção, Xavier indica que os sujeitos que praticam atividades digitais são capazes de, entre outras coisas,

Apreender, gerenciar e compartilhar os novos conhecimentos aprendidos com os parceiros de suas comunidades virtuais; checar online a veracidade das afirmações apresentadas e refutar com base em dados disponíveis na rede, a fim de exercitar a crítica a posicionamentos e não simplesmente acolher de tudo o que se diz na Internet como verdades incontestáveis. Explorar e contemplar as formas de arquitetura escolhida para apresentar as ideias materializadas em discursos hipertextuais, os quais se valem tanto do sistema semiótico verbal quanto do visual e do sonoro como estratégia multissemiótica para se fazer entender entre as inúmeras páginas indexadas diariamente à grande rede. (XAVIER, 2007, p. 8)

Para o autor, o exercício diário de tais atividades (apreender, gerenciar e compartilhar novos conhecimentos, checar afirmações online etc.) exigem dos sujeitos um considerável esforço mental para realizá-las. São desafios aos quais nós, inconsciente e voluntariamente, somos submetidas, de modo que precisamos enfrentá-los, caso queiramos continuar a interagir por meio de uma potente máquina que conecta pessoas a distância e fornece-lhes imagens, sons e textos.

Esse cenário sócio-educacional começou a se modificar, entre as décadas de 1980 a 1990, com a inserção dos computadores pessoais na vida cotidiana, com o surgimento da internet e dos modos de digitalização das práticas sociais. Estas novas tecnologias, chamadas de Tecnologias da Informação e Comunicação, doravante $\mathrm{TIC}$, acrescentaram à cultura grafocêntrica outras formas de realização da leitura e da escrita, agora não mais realizadas por meios físicos como cadernos, livros, bibliotecas, cópias no papel, ou mesmo com instrumentos como o lápis, a caneta e a borracha. 
Como todo novo advento, estes também demandam novas aprendizagens para se lidar com o que está em emergência, pois, como defende Hasan (1996, p. 378), "a multiplicidade de significados atribuídos ao letramento sugere que ele é um processo multifacetado que contém fenômenos de diversos tipos", entre estes o letramento digital. Assim, essas TIC demandaram aprendizagens como o uso dos equipamentos de informática, o saber digitar, a leitura de ícones, a possibilidade de realização de multitarefas, a confiabilidade numa relação com uma "máquina inteligente", a compreensão do funcionamento de uma rede, correio eletrônico, entre tantos outros saberes, isto é, outros letramentos, para além da cultura do papel $^{1}$.

Nesse sentido, a inserção das TIC no currículo escolar inundou as discussões educacionais sobre diversas questões, como o futuro do livro impresso/digital, a propriedade da autoria, aulas presenciais ou em ambientes digitais, entre tantas outras. E, nesse oceano de indagações, a questão da necessidade de se letrar digitalmente surgiu como uma emergência, pois, concordando com Bazerman (2007, p. 18), "não se pode viver como parte de uma comunidade contemporânea sem participar da leitura e da escrita". Adaptando essa necessidade para o nosso objeto de análise, não basta mais ensinar e aprender ler e escrever, é preciso saber ligar/desligar o computador, digitar, fazer busca na internet (googlar ${ }^{2}$ alguém ou alguma coisa), conectar-se, formatar trabalhos, dominar o mouse, entre tantas outras demandas (mesmo que tentemos delimitá-las, o movimento de alteração e atualização é contínuo).

Esse fluxo contínuo de transformações afetou o campo de estudos da linguagem. De acordo com Souza (2007), a linguagem da era digital tem se transformado mais rapidamente do que em outros contextos anteriores de evolução linguística. Tal fato abriu a possibilidade para novos estudos em linguagem, formas de expansão e interação com o ciberespaço, os novos gêneros textuais dos meios digitais, a sintaxe própria do hiperespaço e, entre estes tópicos, o fenômeno do letramento digital.

Esse fenômeno vem sendo denominado de várias maneiras, em sua maioria termos oriundos do inglês "computer literacy", "information literacy", "e-literacy", "network literacy" e "media literacy", e também em português, como letramento informacional, letramento computacional, letramento midiático, letramento multimidático. Dado como um fenômeno complexo, o conceito de letramento digital foi apresentado

1 Em referência aos outros suportes que emergiram com as tecnologias da atualidade, ver Chartier, 1999.

2 Isto é, digitar o nome de algo ou alguém no site de buscas www.google.com.br 
pela primeira vez por Paul Glister (1997), não como um conjunto de habilidades para utilizar o computador, mas sim como "an ability to understand and to use information from a variety of digital sources" (BAWDEN, 2008, p. 18).

Como precursores do conceito de letramento digital, houve o termo alfabetização tecnológica (utilizada por Andrew Molnar, ex-diretor do Office of Computing Actives, da Nacional Science Foundation, em 1972), que se referia ao aprendizado das técnicas de uso de aplicativos. Essa expressão foi utilizada por Frade (2007) como alfabetização digital incorporando a mudança lexical, o conceito foi ampliado, levando-o de aprendizado de técnicas para o uso de mídias digitais, de computadores, incluindo escrever e ler textos nesse novo suporte.

Dessa forma, este artigo tem por objetivo apresentar uma análise das principais concepções de letramento digital, de acordo com a literatura da área, especificamente Xavier (2007, 2011), Lankshear; Knobel (2008), Soares (2002), entre outros. Em seguida, propomos um novo olhar para o fenômeno e, como consequência, um novo conceito. Esta nova perspectiva aborda o letramento digital como um rizoma (DELEUZE \& GUATTARI, 1995), dados os seus princípios, como conectividade, heterogeneidade, multiplicidade, ruptura, cartografia e decalque, que marcam a permanência e fugacidade no entendimento do letramento digital e delineiam a complexidade do fenômeno.

Acreditamos que o conceito de rizoma incorpora melhor as perspectivas tanto do fenômeno "letramento digital" quanto dos sujeitos produtores e produtos desse processo. Assim, a noção de rizoma, para nós, implica o entendimento de um mapa, que, nas palavras de Deleuze e Guattari (2009, p. 22), "é aberto, é conectável em todas as suas dimensões, desmontável, reversível, suscetível de receber modificações constantemente". Assim como fenômeno do letramento digital que, se desenha à medida que vai se desenvolvendo, se atualizando, podendo se redesenhar, se conectar a outros conhecimentos para se construir.

Em termos de organização, o artigo está estruturado em cinco seções, além desta introdução, a primeira seção, na qual apresentamos o momento sóciohistórico e seus habitantes. Em seguida, a segunda e a terceira partes, nas quais apresentamos o mapa conceitual do letramento digital internacional e nacional, para construir, nesta esteira, o terreno rizomático do conceito que propomos, na quarta parte. Por fim, a conclusão, na qual tecemos as considerações finais sobre este trabalho epistemológico. 


\section{OS TEMPOS VIVIDOS DE AGORA: A CIBERCULTURA}

O cenário da pós-modernidade ganhou seus contornos após 1945, com o trágico fim da segunda Guerra Mundial, que faria despencar as concepções antigas e abriria espaço para novas formas de pensar. A ciência produzida a partir dessa época investe-se de um viés tecnológico, o qual buscaria entender, entre tantas outras questões, processos como a linguagem ou áreas ainda inexploradas do corpo humano, como o cérebro. Desse desenvolvimento, surgirá, por exemplo, o campo de estudos da inteligência artificial, a telemática, as linguagens de programação, a semântica cognitiva e a cibernética.

A sociedade contemporânea ocidental experimentava, então, a incredulidade frente às teorias antigas, como vimos, a partir do final da década de 1940, a explosão do consumo impulsionada pela propaganda, a partir da década de 1960, e novas formas de comunicação e atuação sociais, com o surgimento dos computadores e outros dispositivos eletrônicos, a partir do final da década de 70. A união desses fatores produz um novo modo de entender a sociedade: a cibercultura. Segundo Lemos,

A cibercultura é a cultura contemporânea marcada pelas tecnologias digitais. Vivemos já a cibercultura. Ela não é o futuro que vai chegar mas o nosso presente (home banking, cartões inteligentes, celulares, palms, pages, voto eletrônico, imposto de renda via rede, entre outros).

(LEMOS, 2003, p. 11-12)

Assim, já vivemos a cibercultura, não será o futuro e sim o nosso agora, o presente, marcado pela presença de dispositivos eletrônicos, internet, comunicação massiva e muitas informações.

O domínio da tecnologia como um certo determinismo técnico, apontado por muitos autores como a marca do novo tempo, acertou em cheio a sociedade, mas não de uma forma pessimista e fatalista e, sim, como uma presença que é o resultado da "evolução da cultura técnica moderna" (LEMOS, 2003, p. 12).

A cibercultura tem suas raízes no pensamento cibernético, de controle e transformação do mundo em dados binários. Segundo o dicionário eletrônico Houaiss, a palavra chegou até nós por meio do inglês cybernetics, datado de 1948, resultado da importação do grego kubernétikê (sc. tekhnê), que remetia a "arte de pilotar, arte de governar".

O pioneiro no uso e estudo do termo foi o matemático norte-americano Norbert Wiener, que entendia a cibernética como a teoria que engloba a mente, o corpo humano e o mundo das máquinas. Goés (2007, p. 33) explica que para Weiner, "um corpo está aquém de um mero receptor e acumulador de energia e 
mais para uma rede comunicacional baseada na recepção e troca de sinais no tempo e no espaço".

O entendimento de Weiner não se encontrava isolado na metade do século XX. Antes dele, o matemático inglês, Alan Turing, fizera a demonstração de que qualquer enunciado poderia ser descrito por meio de uma formalização, executada por meio de uma máquina, cunhada como máquina universal.

Esse entendimento e demonstração viriam a mudar completamente a relação dos homens com as máquinas, já que estas, agora, assumiriam a rica função humana de "pensar". A máquina de Turing, como passou a ser conhecida, operava com um código binário (do tipo on/off, sim/não, ou 0/1) e teve como marco o fato de mecanizar qualquer cálculo lógico-matemático, o que viria a possibilitar a invenção e construção dos computadores que conhecemos hoje. E, também, talvez mais interessante ainda, foi o fato de que a criação de tal máquina tenha impulsionado o entendimento da mente humana, mesmo que a compreendendo como uma máquina.

É fato que a máquina de Turing não se ocupava de questões como o significado de símbolos ou expressões, ela apenas demonstrava que calcular era uma habilidade mecânica, portanto, executável por uma máquina. Esse fato gerou euforia entre a comunidade científica que passou a entender que pensar fosse calcular e que, portanto, a máquina pensava. Obviamente, o pensar aqui referido restringia-se ao pensamento lógico-matemático racional.

Dupuy (1995) aponta o fato de que o grupo de matemáticos, engenheiros e fisiologistas (cibernéticos) buscava a edificação de uma ciência da mente, entendida aqui como um computador, que vem, então, a partir dessa concepção, servir de modelo para se conceber a mente humana. Sem nos afetarmos pela relação máquina e homem, o que a teoria cibernética propunha era um entendimento unificado da máquina com a vida, "tendo por base a categoria da finalidade pensada em termos mecanicistas e rebatizada como "teleologia". Tratava-se, (...) de uma ciência das analogias entre máquinas e organismos" (SANTAELLA, 2004, p. 75).

A teoria de Weiner sobre a cibernética influenciou a criação de outro termo, o ciberespaço. Inventado e utilizado por William Gibson, no romance ficcional e célebre Neuromancer, o ciberespaço é

\footnotetext{
Uma alucinação consensual, vivida diariamente por bilhões de operadores legítimos, em todas as nações, por crianças a quem estão ensinando conceitos matemáticos. Uma reprogramação gráfica de dados abstraídos dos bancos de todos os computadores do sistema humano. Uma complexidade impensável. Linhas de luz alinhadas que abrangem o universo não-espaço da mente, nebulosas e constelações infindáveis de dados. (GIBSON, 1991, p. 56-57)
} 
Com a ficção, a realidade. A inserção dos computadores nos lares mundiais e a autonomia do usuário transformaram o ciberespaço no novo meio de comunicação, interconectando todos os computadores, num universo de conhecimentos e informações, numa única rede, a internet.

Para Santaella, o ciberespaço deve ser entendido como "um mundo virtual global coerente, independente de como se acede a ele e como se navega nele" (SANTAELLA, 2004, p. 40). É o mundo que se abre ao usuário quando este se conecta à rede, e, devido à mobilidade dos recursos para se executar esse ato, o ciberespaço passou a ser "um mundo virtual da comunicação informática, um universo etéreo que se expande indefinidamente mais além da tela, por menor que esta seja, podendo caber até mesmo na palma de nossa mão" (SANTAELLA, 2004, p. 45-46).

As possibilidades de exploração do ciberespaço trouxeram uma nova perspectiva à comunicação humana, pela facilidade de acesso e disponibilidade. A partir dos anos 1970, a tecnologia atinge a esfera das comunicações, e uma nova mídia surge: a hipermídia.

Santaella (2004) afirma que a hipermídia apresenta quatro traços definidores, sendo que o primeiro deles é a hibridização de linguagens, processos com signos, códigos e mídias que a hipermídia aciona e mescla para produzir sentidos na medida em que o usuário (leitor) interage com ela. O segundo traço definidor é a "organização reticular dos fluxos informacionais em arquiteturas hipertextuais" (SANTAELLA, 2004, p. 48), ou seja, a capacidade de guardar as informações e disponibilizá-las para o usuário que, a partir de sua própria volição, interliga as informações criando novos textos, tornando-se um coautor. O que só é possível "devido à estrutura de caráter hiper, não sequencial, multidimensional que dá suporte às infinitas opções de um leitor imersivo" (SANTAELLA, 2004, p. 49).

A quantidade de informações disponíveis na rede ou em meios digitais é gigantesca, criando um labirinto de infovias que se entrelaçam e se separam de acordo com os caminhos da navegação. Para Santaella, esse seria a terceiro traço definidor da hipermídia, o cartograma navegacional, o qual requer o quarto traço definidor, a interatividade. De acordo com ela,

O leitor não pode usá-la de modo reativo ou passivo. Ao final de cada página ou tela, é preciso escolher para onde seguir. É o usuário que determina qual informação deve ser vista, em que sequência ela deve ser vista e por quanto tempo. Quanto maior a interatividade, mais profunda será a experiência de imersão do leitor, imersão que se expressa na sua concentração, atenção, compreensão da informação e na sua interação instantânea e contínua com a volatilidade dos estímulos. (SANTAELLA, 2004, p. 52), 
Outro fator importante da hipermídia é o caráter libertador dos constrangimentos entre tempo e espaço. Segundo Lemos (2003, p. 13), "a convergência da informática com as telecomunicações vai dar origem ao que se vem chamando de sociedade da informação ou informacional", bem como mostrou Castells.

Nesse sentido, se a modernidade pode ser caracterizada como a época de apropriação da técnica, a cibercultura apropriou-se das formas de comunicação sociais e midiáticas derivadas das técnicas. A comunicabilidade aliada à queda dos metarrelatos e a possibilidade de fim do mundo estão no cerne da ideia do que representa a cibercultura.

Este breve percurso histórico sobre a tecnologia (cibernética e cibercultura) nos ensina que os sujeitos produzem seus artefatos históricos e intelectuais, adaptando-se ao mundo a sua volta. Desde o final do século XX, vivemos imersos em realidades alternativas, tempos e espaços diferenciados, em que os novos dispositivos tecnológicos "incidem sobre todas as formas de produção de enunciados, imagens, pensamentos e afetos" (Parente, 1999, p. 14).

Desse hibridismo cultural e coexistência de mídias, incentivado e recriado pelos sujeitos viventes dessas práticas, emergem modificações nas formas de viver e na linguagem. Inseparável da sociedade, a linguagem acompanha as mudanças sociais, modificando-se junto aos seres que a manifestam. Assim, novos dispositivos, novas palavras para designá-los e utilizá-los, outras necessidades de outros letramentos, como o letramento digital.

\section{LETRAMENTO DIGITAL NO CENÁRIO INTERNACIONAL}

Internacionalmente, o termo letramento digital é objeto de pesquisa de vários grupos de estudo, como École Normale Superior ${ }^{3}$, em Cachan, na França, o grupo de estudos de I. Snyder, na Austrália e as discussões realizadas pelo grupo norte-americano composto por Knobel e Lankshear (2008).

O grupo de estudos da École Normale Superior desenvolve diversas pesquisas a respeito dos usos e efeitos da tecnologia na educação, em vários níveis. Já o grupo australiano, liderado por Snyder (1997), aborda o letramento digital como "letramento eletrônico" ou "ciberletramento", diferenciando o letramento convencional do eletrônico, cuja definição seria um conjunto de conhecimentos ou habilidades indispensáveis para responder adequadamente às demandas sociais 
de uma nova era digital. Esse conceito está mais inserido na perspectiva do uso da máquina, do computador.

Esses grupos colaboram com a temática do letramento digital em outra alçada, na qual não nos desenvolveremos aqui. Já o grupo norte-americano aborda o letramento digital dentro da perspectiva dos multiletramentos, por esta escolha teórico-metodológico basear-nos-emos nesses pesquisadores para as análises aqui realizadas.

Knobel e Lankshear desenvolvem, a partir do conceito proposto por Street ${ }^{4}$ (1984), estudos sobre os novos letramentos. Seus trabalhos iniciais sobre a temática articulavam o letramento digital aos letramentos críticos, Lankshear (1997) e Lankshear e Knobel (1998), inserindo uma visão sociocultural do fenômeno, que abrangia componentes operacionais, culturais e críticos, nas práticas realizadas por meio da leitura e da escrita em meios digitais. A atenção dos autores estava voltada para compreender como essas novas práticas de leitura e escrita produzem sentidos, constroem mundos em linguagem para estudantes (crianças e adolescentes) do mundo inteiro.

Em trabalhos mais atuais, Lankshear e Knobel (2008) propõem que os letramentos digitais representam diversas formas de prática social, as quais emergiriam e se modificariam em novas práticas, podendo, inclusive, ser substituídas por outras. Isso porque o letramento digital é parte de um conjunto de ideias, enfocado os aspectos cognitivos e sócio-emotivos envolvidos nas atividades em ambiente digital, e também um conjunto de habilidades e técnicas específicas necessárias para qualificar o indivíduo como letrado digitalmente.

Os autores basearam sua compreensão sobre o fenômeno nos postulados de Street (1984) e de Gee (1996), e justificam que o termo "letramentos digitais", no plural, responde melhor ao novo cenário social e educacional, pois prioriza a enorme quantidade de práticas sociais que envolvem tal fenômeno, além de implicar uma mobilização de políticas vinculadas a uma perspectiva sociocultural do letramento.

A perspectiva de letramentos também recobre questões de aprendizado de leitura e escrita, segundo Knobel e Lankshear (2008). Os autores explicam que ser letrado digitalmente habilita os sujeitos a entender e a produzir mensagens em novos gêneros textuais, pois como usuários frequentes, os seres digitais estão

\footnotetext{
4 Cunhado por Street, o termo letramento assumiu novo significado a partir de vários estudos, em sua grande parte, etnográficos, que se preocupavam com o impacto da escrita em diversas sociedades. Já no Brasil, o termo passou a figurar no cenário acadêmico a partir da publicação da obra de Soares (1998), a qual distinguiu alfabetização de letramento, mesmo que tenha aparecido anteriormente, como em Kato (1986).
} 
imbuídos dessas novas práticas sociais. Entendem memes ${ }^{5}$ da internet, compreendem imagens tratadas em photoshop e respondem bem a expressões como LOL ${ }^{6}$.

A capacidade de entender essas práticas sociais veiculadas por computador plugado à internet é representativa do que Knobel e Lankshear (2008) entendem por letramentos digitais e que habilitará os indivíduos a lidar com novas e variadas informações de diferentes fontes e se comunicarem. São exemplos destas práticas os processos de montagem e remixagem, os blogs, os processos de compra e venda online e as redes sociais digitais

Outro aspecto importante ressaltado é a questão da agência. Os autores observam que a perspectiva de letramentos digitais abriria um caminho para a conexão de letramento, aprendizagem e o significado com experiências de agência, eficácia e prazer. Eles criticam a importação de práticas de letramento digital para a sala de aula apenas por serem mais atraentes ou por ocasionarem sucesso àqueles alunos que não respondiam bem aos métodos tradicionais de ensino. E também propõem que o letramento digital sirva para construir pontes entre os interesses dos alunos e os fins acadêmicos.

O fenômeno do letramento digital também vem sendo investigado por instituições não acadêmicas, como no caso do relatório Digital Transformation ${ }^{7}$, publicado em 2007. Esse documento entende, numa perspectiva mais ampla, que o letramento digital abrange além das habilidades técnicas, também as habilidades cognitivas necessárias para a aplicação das habilidades técnicas e conhecimentos, em um continuum de competências e habilidades. Desse modo, o cenário do letramento digital varia de usos simples da tecnologia na vida cotidiana para usos complexos de realização de tarefas.

Assim, o documento define o letramento digital como sendo "ICT literacy is using digital technology, communications tools, and/or networks to access, manage, integrate, evaluate, and create information in order to function in a knowledge society". Essa definição apresenta cinco componentes para o letramento digital,

5 Um meme de internet refere-se a uma série de pessoas, vídeos, imagens, ou mesmo um remix, que se populariza e se espalha na internet.

6 LOL é um acrônimo para a expressão em língua inglesa "laugh out loud" que corresponde em português a "muitas risadas", "rindo muito alto". Geralmente é utilizado em conversas durante partidas de jogos online ou mensagens instantâneas.

7 Esse documento é o resultado de um painel internacional desenvolvido pelo Educational Testing Service (ETS), composto por especialistas em educação e organizações não-governamentais (ONGs), de países como Austrália, Brasil, Canadá, França e Reino Unido. O tema do estudo foi a crescente importância da informação e Tecnologias da Comunicação (TIC) e sua relação com o letramento. O documento original está disponível em: <http://www.ets.org/Media/Tests/ Information_and_Communication_Technology_Literacy/ictreport.pdf $>$ Acesso em 10 de outubro de 2011. 
os quais representam um conjunto crescente de habilidades e conhecimentos, como habilidade/conhecimento de como coletar e/ou recuperar informações; de organizar, categorizar em esquemas de classificação as informações; de interpretar e representar a informação, resumir, comparar, contrastar; de julgar sob critérios como qualidade, relevância, utilidade, eficiência da informação e de gerar informações a partir da adaptação, aplicação, desenho ou criações.

No mesmo sentido de habilidades, porém com muito mais profundidade técnica, as pesquisadoras Ward e Karet (1996) estabeleceram um roteiro baseado em conteúdo para o letramento digital, com seis habilidades mestras. São elas: usar com proficiência, configurar, gerenciar, selecionar opções, entre outros, mecanismos com o e-mail, o browser da internet, usar códigos para a construção de páginas, habilidade de linkar ${ }^{8}$ conteúdos, anexar imagens, usar ferramentas de comunicação em tempo real, entrar em outros servidores, acessar arquivos, usando o FTP (File Transfer Protocol) e usar o USENET newsgroups ${ }^{9}$ e bulletin boards.

Essas habilidades situam-se no domínio do sistema computacional, que, ao serem alcançadas, deslocariam o usuário comum para outras funções e usos do computador, como gerenciar, criar, modificar sistemas de informação.

Posição interessante assume o professor Eshet-Alakalai (2004), da Universidade de Israel, a respeito do letramento digital. Para esse autor, o letramento digital compreende um domínio formado por outros letramentos, como o letramento foto-visual, o letramento de reprodução, letramento de ramificação, letramento de informação e o letramento socioemocional, o que pode nos ajudar a compreender como os "users perform with tasks that require the utilization of different types of digital skills" (ESHET-ALAKALAI, 2004, p. 94).

Assim, o letramento foto-visual, já tratado por Snyder (1997), retoma a antiga forma de leitura baseada apenas no visual, quando ainda não havia letras, alfabeto. Nesse mesmo percurso, Eshet-Alakalai (2004, p. 95) afirma que os usuários de mídias digitais empregam "a unique form of digital literacy - photo-visual literacy that helps them to "read" intuitively and freely, and to understand the instructions and messages represented visually".

Em consonância com o quadro conceitual de Eshet-Alakalai (2004), o letramento de reprodução refere-se às novas formas de arte da pós-modernidade,

8 Apropriando-nos do verbo em inglês to link para construção em português, já comum no vocabulário internetês.

9 Usenet é um meio de comunicação no qual os usuários podem postar mensagens de texto (artigos) em fóruns, já o bulletin board é um sistema de informações que permite a conexão via telefone a um sistema através do seu computador e interagir com ele, tal como a internet. 
com a crítica à morte do autor, a partir da questão da reprodutibilidade técnica ${ }^{10}$ (BENJAMIN, 1994). Esse letramento permite a criação de uma obra significativa, autêntica e criativa, integrando diversas partes de informação disponíveis na rede. Para tanto, faz-se necessário o letramento de ramificação, que, por sua vez, integra as possíveis vias de informação disponíveis no entrecruzamento de links e hipertextos.

As ramificações aqui remetem ao conceito de rizoma e possibilitam a montagem de um mapa livre, em diversos domínios do conhecimento, com amplas possibilidades de navegação. Contudo, isto acarreta a difícil tarefa de construir conhecimentos com tantas peças de informação, dispostas não-linearmente. EshetAlakalai (2004, p. 100) indica, ainda, que o letramento de ramificação promove o pensamento multidimensional, e constitui uma habilidade de sobrevivência para a execução de tarefas, na era da informação.

Esse conhecimento interage com o próximo letramento, o da informação, o qual se refere às habilidades cognitivas que filtram a informação. É extremamente necessário o desenvolvimento desse tipo de letramento, dada a dificuldade de se avaliar perante a avalanche de informações às quais temos acesso no cotidiano de navegação na web.

Por fim, o autor explica o conceito de letramento socioemocional que, por envolver aspectos do campo social e emocional dos sujeitos, parece ser o mais complexo de todos. Exige dos usuários criticidade para julgar a informação e o andamento da interação na internet; ao mesmo tempo, qualifica os usuários como competentes compartilhadores de conhecimentos, com capacidade de avaliação, informação e de pensamento abstrato, e ainda, como construtores de conhecimentos de forma colaborativa.

O panorama de conceitos que molda o letramento digital, para EshetAlakalai, demonstra como esse fenômeno se revela amplo e complexo, e exige uma interpretação integrativa para seu entendimento.

\section{LETRAMENTO DIGITAL NO CENÁRIO NACIONAL}

No cenário nacional, algumas definições já cercam o termo, entre as quais podemos destacar a de Soares (2002), que revisou seu próprio conceito de letramento (1998) a partir do momento atual, a cibercultura. Nesta fase, Soares acrescenta sobre seu conceito anterior que

10 A questão da reprodutibilidade técnica foi tratada pelo filósofo da Escola de Frankfurt, Walter Benjamin (1994). 
O momento atual oferece uma oportunidade extremamente favorável para refiná-lo e tornálo mais claro e preciso. É que estamos vivendo, hoje, a introdução, na sociedade, de novas e incipientes modalidades de práticas sociais de leitura e de escrita, propiciadas pelas recentes tecnologias de comunicação eletrônica - o computador, a rede (a web), a Internet. É, assim, um momento privilegiado para, na ocasião mesma em que essas novas práticas de leitura e de escrita estão sendo introduzidas, captar o estado ou condição que estão instituindo: um momento privilegiado para identificar se as práticas de leitura e de escrita digitais, o letramento na cibercultura, conduzem a um estado ou condição diferente daquele a que conduzem as práticas de leitura e de escrita quirográficas e tipográficas, o letramento na cultura do papel. (SOARES, 2002, p. 16)

Nesse sentido, a cibercultura configura-se como um momento profícuo para que os sujeitos possam se conduzir a um novo estágio de letramento, que poderá desempenhar "um papel de organização e reorganização desse estado ou condição" de letramento (SOARES, 2002, p. 148). Vale acrescentar que os eventos de letramento decorrem das práticas sociais de leitura e escrita que emergem na sociedade; nesse caso, prática de leitura e escrita digitais emergem do uso da Internet, computadores e similares cada vez mais comuns nas atividades dos sujeitos contemporâneos.

Soares, então, chega ao conceito de letramento digital em oposição ao de letramento e o define com certa instabilidade como sendo

Um certo estado ou condição que adquirem os que se apropriam da nova tecnologia digital e exercem práticas de leitura e de escrita na tela, diferente do estado ou condição - do letramento - dos que exercem práticas de leitura e de escrita no papel. (SOARES, 2002, p. 151)

Essa definição, embora bastante pertinente, restringe os eventos de letramento a práticas de leitura e escrita efetuadas diante das telas, com certa apropriação. É pertinente porque nos remete, no caso da apropriação, a uma espécie de gradiente, graus de letramento, mas é restritiva porque entendemos que os eventos de letramento digital, embora em sua maior ocorrência se deem a partir da interação com a tela de computadores, telefones celulares, Ipods, Ipads e tantos outros, evocam um algo mais, que, no nosso entendimento, relaciona-se com a identidade dos sujeitos, com a postura frente ao digital, ao virtual, ao online, a aquilo que está na nuvem ${ }^{11}$.

11 Estar na nuvem é manter seus arquivos (fotos, documentos, músicas) em serviços de armazenamento online. Pré-requisitos do comportamento online, a ubiquidade e a mobilidade são responsáveis pela necessidade de compartilharmos e acessarmos nossos arquivos onde quer que estejamos com facilidade e rapidez. Dessa forma, serviços como Dropbox, Drive, Onedrive, multiplicam-se na internet. Alguns são gratuitos, outros oferecem mais espaço e vantagens por algum valor. 
Já o linguista brasileiro L. A. Marcuschi (2008), quando tratou dos gêneros textuais digitais, realizando um minucioso levantamento destes e suas características, numa relação entre forma e função, conferiu à tecnologia um importante papel sóciohistórico em relação ao desenvolvimento da comunicação e da sociedade humana. Marcuschi propõe que "pode-se dizer que o discurso eletrônico ainda se acha em estado meio selvagem e indomado sob o ponto de vista linguístico e organizacional" (MARCUSCHI, 2008, p. 199). E questiona:

É possível indagar-se que tipo de prática social emerge com as novas formas de discurso virtual pela internet. Pode-se falar em letramento digital, como foi inicialmente sugerido? Creio que é cedo para tanto. Mas já se pode dizer que temos novas situações de letramento cultural. (MARCUSCHI, 1008, p. 199)

Acreditamos que, como fenômeno, o letramento digital já emergiu e cabe aos linguistas, pesquisadores e estudiosos dos fenômenos da linguagem, delimitálo, entendê-lo e desenhar sua cartografia. Como colaboradores para a delimitação desse fenômeno, no Brasil, podemos citar a publicação do ano de 2007, intitulada "Letramento digital e ensino", de viés linguístico e educacional de A. C. Xavier, cuja tese sobre o hipertexto foi uma das pioneiras sobre o tópico.

Para esse autor, o letramento digital refere-se a um conjunto de habilidades que estão, na sociedade atual, intrinsicamente vinculadas à cidadania, e incorpora novas práticas de leitura e escrita. Tais práticas são diferentes das tradicionais pois agora podem se realizar em formato digital, nas telas de computadores, telefones celulares (smartphones), iphone, ipods, tablets, o que "pressupõe assumir mudanças nos modos de ler e escrever os códigos e sinais verbais e não-verbais, como imagens e desenhos" (Xavier, 2007, p. 135).

Para tanto são necessários habilidades e conhecimentos tanto da alfabetização quanto do letramento, pois é preciso integrar esses conhecimentos para uma prática eficiente nos eventos de letramento digital. Assim, Xavier propõe o seguinte esquema: 


\section{LETRAMENTO \\ Gêneros textuais/digitais}

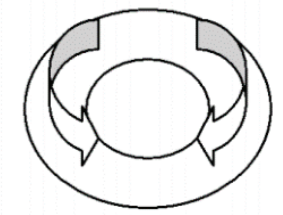

\section{Práticas Sociais}

Eventos (de letramento)

Figura 1: Elementos do letramento

A ilustração mostra que a integração entre estes três elementos (Práticas Sociais e os Eventos de Letramento e os Gêneros textuais/digitais) resulta em práticas de letramento bem sucedidas, que envolvem tanto o sujeito, quanto a comunidade, o poder político, a fim de "estimular e financiar a construção de telecentros públicos (...), equipar as escolas do ensino fundamental e médio com laboratórios de computação, capacitar em massa seus professores, transformandoos em 'letrados digitais'" (2007, p. 142).

Em outro momento, Xavier (2011) desenvolveu um estudo, de cunho exploratório longitudinal, que investigou o desenho conceitual e prático do letramento digital entre adolescentes de uma escola particular de Recife-PE. A pesquisa acompanhou por oito meses as atividades com ferramentas digitais realizadas por esses sujeitos na escola, individual e coletivamente. Durante as filmagens, os sujeitos eram questionados a respeito de como, quando, onde e por que utilizavam computadores, programas, telefone celular e jogos eletrônicos.

Os resultados desse estudo mostraram que esses sujeitos tinham acesso a computadores conectados à internet desde muito cedo, manuseavam as ferramentas de comunicação a distância como e-mail e programas de mensagens instantâneas com frequência, passavam, em média, mais de duas horas conectados por dia, com tendência a ampliar esse tempo à medida que a idade aumentava. A pesquisa mostrou que, entre os adolescentes investigados, a maioria deles apresentava um bom domínio das novas mídias digitais de informação e comunicação, pois, como disse o autor: "nasceram imersos no modus vivendi digitale" (XAVIER, 2011, p. 9).

Concordando com a perspectiva de Xavier, Buzato trata de letramentos digitais como sendo 
Conjuntos de letramentos (práticas sociais) que se apoiam, entrelaçam, e apropriam mútua e continuamente por meio de dispositivos digitais para finalidades específicas, tanto em contextos socioculturais geograficamente e temporalmente limitados, quanto naqueles construídos pela interação mediada eletronicamente. (BUZATO, 2006, p. 16)

Buzato (2006) apresenta, então, esse entrelaçamento de elementos como um mapa para a compreensão do fenômeno do letramento digital e que se complementa com o que Souza propõe como sendo:

O conjunto de competências necessárias para que um indivíduo entenda e use a informação de maneira crítica e estratégica, em formatos múltiplos, vinda de variadas fontes e apresentada por meio do computador, de maneira crítica e estratégica, sendo capaz de atingir seus objetivos, muitas vezes compartilhados social e culturalmente. (SOUZA, 2007, p. 60)

Pesquisadoras brasileiras sobre o tema do letramento digital, com diversas publicações na área, Coscarelli e Ribeiro (2007, p. 9) entendem o fenômeno como "letramento digital é o nome que damos, então, à ampliação do leque de possibilidades de contato com a escrita também em ambiente digital (tanto para ler quanto para escrever) ". Nesse sentido, o letramento digital, para as autoras, assume uma continuidade do conceito de letramento, modificando-se o ambiente em que novas práticas se desenvolverão, agora em ambiente digital, sendo necessário um conhecimento básico de recursos de informática.

Todavia, a transposição das atividades de um meio a outro não é suficiente para o alcance de um fenômeno tão amplo como o letramento digital. Entendemos que as definições aqui mostradas desenham um cenário complexo que entrelaça as práticas sociais, os contextos socioculturais e os dispositivos eletroeletrônicos que são os componentes fundamentais para o fenômeno do letramento. Ainda consideramos importante um aspecto não aprofundado nas perspectivas anteriores que se relaciona à volição dos sujeitos envolvidos pelo fenômeno.

Portanto, para nós o letramento digital refere-se ao conjunto de conhecimentos envolvidos em práticas linguístico-sociais realizadas por mídias digitais. As práticas, por sua vez, envolvem, além de habilidades técnicas, habilidades de leitura, modos de interagir, comunicar, compartilhar e compreender o sistema de mídias como constituintes de mundo contemporâneo e de suas práticas sociais.

Sendo formado por um conjunto de elementos, este conceito pressupõe seu desenvolvimento em um continuиm, que envolve diversos fatores como maturidade biológica e cognitiva, ambiente socioeconômico propício, momento históricocultural atualizado e interações com modos de ser digitalizados. Esclarecendo melhor esses fatores, diríamos que: 
a) Maturidade biológica e cognitiva é a necessidade de o mínimo de controle motor para que se interaja com as mídias digitais, pois é preciso segurar o mouse, guiar seu cursor, tocar a tela, movimentar-se por um hipertexto, entre outros movimentos biomecânicos impulsionados pela decisão intelectual do usuário para efetuá-los. Além disso, é necessário que haja maturidade cognitiva para entender os processos que envolvem um jogo, uma leitura hipermidiática, a navegação em sites etc.

b) Ambiente socioeconômico é a condição que compreende o ambiente por onde o sujeito transita que pode apresentar riqueza de interação com as mídias digitais, favorecendo seu aprendizado ou não;

c) Momento histórico-cultural atualizado: compreende viver a partir do final do século XX, quando os movimentos de cibercultura adentraram a sociedade e nela permaneceram, em que os modos de estar online e offline não constituem oposição, sendo o online o modo como a nova geração entende a vida;

d) Interações com modos de ser digitalizados: compreendem os momentos de interação com as mídias digitais, isto é, movimentos de compartilhamento, leitura hipertextual, navegação na rede, comportamento online, entre outros.

Ainda, entendemos que esse conceito implica um sujeito que viva e compartilhe de seu mundo de forma digital e que, mesmo que os equipamentos de informática não sejam acessíveis, ele entenda o sistema de mídias como parte de como as coisas funcionam no mundo. Parece-nos que o entendimento desses fatores numa perspectiva rizomática encaixa-se bem ao fenômeno do letramento digital. Entretanto, cabe-nos agora delimitar que conhecimentos e habilidades são caracterizadores do letramento digital, numa perspectiva rizomática.

\section{UM OLHAR RIZOMÁTICO SOBRE O CONCEITO DE LETRAMENTO DIGITAL}

O pensamento binário orienta o ocidente desde a antiguidade clássica. A formação dos conceitos dá-se, em geral, pela parte e sua contraparte, como sujeito/objeto, racionalidade/subjetividade. Para Deleuze e Guattari (2009, p. 29), "no Ocidente a árvore plantou-se nos corpos, ela endureceu e estratificou até os sexos". Pensamos por oposição, separação, conceituação e classificação. Criamos categorias estáticas e aprisionamos os conceitos a estas. Todavia, em tempo de 
pós-modernidade, no qual a queda das metanarrativas arrastou o ocidente para a incerteza e liquidez, a estratificação revelou-se como falha, principalmente no campo linguístico e educacional, no qual encontramos novas formas de subjetivação.

Nesse sentido, o rizoma, segundo a teoria de Deleuze e Guattari (1995), se desenha a partir dos princípios da conectividade, heterogeneidade, multiplicidade, ruptura, cartografia e decalque, que marcam a permanência e fugacidade no entendimento do letramento digital e delineiam a complexidade do fenômeno.

A teoria epistemológica do rizoma preconiza que a organização dos elementos não precisa obedecer a um padrão hierárquico, que representaria a raiz, o poder, e sim, contrariamente, que os elementos se estabelecem em equiparidade, de forma que cada um liga-se aos demais, podendo afetá-los ou incidir sobre eles. Segundo Deleuze e Guattari,

O mundo tornou-se caos, mas o livro permanece sendo imagem do mundo, caosmo-radícula, em vez de cosmo-raiz. (...) Na verdade não basta dizer Viva o múltiplo, grito de resto difícil de emitir. Nenhuma habilidade tipográfica, lexical ou mesmo sintática será suficiente para fazê-lo ouvir. É preciso fazer o múltiplo, não acrescentando sempre uma dimensão superior, mas, ao contrário, da maneira simples, com força de sobriedade, no nível das dimensões de que se dispõe, sempre n-1 (é somente assim que o uno faz parte do múltiplo, estando sempre subtraído dele). Subtrair o único da multiplicidade a ser constituída; escrever a n-1. Um tal sistema poderia ser chamado de rizoma. (DELEUZE; GUATTARI, 2009, p. 14)

Como os autores ressaltam, o rizoma encapsularia o múltiplo revelado em ações, em "fazer o múltiplo". Essa proposta epistemológica surge como uma ruptura ao modelo arbóreo de conhecimento, que se organiza em níveis que vão do menor ao maior, ou vice-versa, estabelecendo subordinação entre seus elementos. No caso do rizoma, mesmo que flexível, existem linhas de solidez e organização estabilizadas por conceitos que sugerem a firmeza do modelo. Podemos descrever rizoma, de acordo com Deleuze e Guattari, como uma:

Haste subterrânea distingue-se absolutamente das raízes e radículas. Os bulbos, os tubérculos, são rizomas. (...) Até animais o são, sob sua forma matilha; ratos são rizomas. As tocas o são, com todas suas funções de hábitat, de provisão, de deslocamento, de evasão e de ruptura. O rizoma nele mesmo tem formas muito diversas, desde sua extensão superficial ramificada em todos os sentidos até suas concreções em bulbos e tubérculos. (DELEUZE; GUATTARI, 2009, p. 15)

Como um sistema aberto, "um rizoma não começa nem conclui, ele se encontra sempre no meio, entre as coisas, inter-ser, intermezzo" (Deleuze e Guattari, 2009, p. 37). Mesmo cercado de exemplificações, os autores desconfiavam de que 
não convenceriam o público leitor se não enumerassem "certas características aproximativas do rizoma", por isso cercaram-no de princípios.

Um rizoma se norteia por princípios de conectividade e heterogeneidade, já que "qualquer ponto de um rizoma pode ser conectado a qualquer outro e deve sêlo" (DELEUZE; GUATTARI, 2009, p. 14), assim como entendemos o fenômeno do letramento digital, que também se conecta aos pontos que desenham seu mapa cartográfico. Este se presume descritivo e, nessa descrição dos fenômenos nem sempre a hierarquia está presente ou é relevante.

No mapa cartográfico do letramento digital, elementos como computador, internet, cibercultura e a escola conquistam o estatuto de catalisadores das mudanças sociais, já que, a partir deles, o processo de mudança ganha movimento, forma e realização. Aliados a estes, podemos destacar o entendimento da sociedade em rede, a globalização, o hipertexto e as redes sociais, os modos de ser online, como fenômenos que tanto cooperam quanto resultam da internet e cibercultura, como componentes do letramento digital.

Podemos ainda ressaltar outros elementos afetados pela internet e computadores e que se relacionam ao letramento digital, como a) o comportamento, que envolve a web 2.0, com sua filosofia de compartilhar, a realização de multitarefa, o zapear; b) a identidade, que vincula os estados online/offline e a cognição; c) as práticas sociais, entre elas os modelos tradicionais de alfabetização (leitura e escrita); d) a segurança e a privacidade; e) a mobilidade e comunicação, atreladas aos dispositivos eletrônicos (smartphones, tablete); f) a comunicação multimídia viabilizada pelo hipertexto formatado em redes sociais, blogues, microblogues, e-mails, aplicativos de mensagens instantâneas; g) o mercado de economia mundial online (e-commerce), em constante mudança desde a globalização.

Os componentes desse mapa cartográfico constituem-se não como unidades isoladas, mas como formadores de um fenômeno, que se conectam e interagem entre si. Entre estes, alguns merecem mais relevância por seu caráter de precedência ao próprio fenômeno, como é o caso da rede mundial de computadores, da cibercultura, pós-modernidade, sociedade em rede e globalização.

Uma forma de se visualizar este mapa cartográfico pode ser a representação oferecida pela Figura 2. 


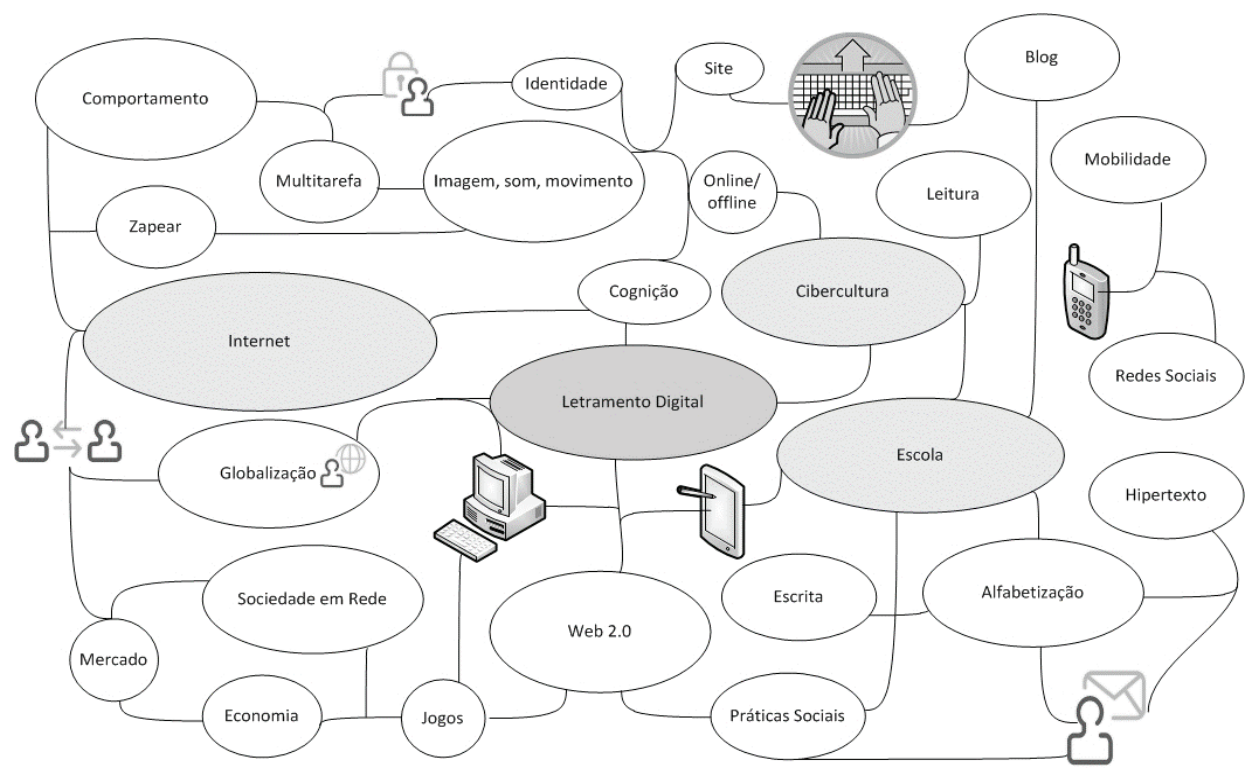

Figura 2: Aspectos do letramento digital representados rizomaticamente

Em certo sentido, a internet ocupa posição mais privilegiada, já que, como quarta mídia, é atualmente a mais consumida e a partir de sua disseminação surgiram outras formas de comunicação, gêneros textuais, formas de comércio, relacionamentos, como as outras partes deste mapa, como o hipertexto, as redes sociais, os sites, os blogues e microblogues.

Alguns dos componentes, que já existiam antes da quarta mídia, despontaram outras performances no ambiente online e por isso revelamse fortemente interligados à internet, como o comportamento, online/offline, a multitarefa, a identidade, os jogos, a economia, as práticas sociais, a segurança, a comunicação, entre outros. Já a alfabetização, leitura, escrita, escola, mesmo que tenham se transformaram com o advento da internet, ainda mantêm seu estatuto de permanência mais aprofundado.

O caráter heterogêneo do rizoma envolve cadeias semióticas de toda natureza, que conectadas colocam em jogo toda a sua diversidade. Um fenômeno de caráter heterogêneo é aquele que possui natureza desigual ou diferença de estrutura, sendo constituído por elementos variados, de diferentes naturezas, não sendo uniforme e podendo ser formado por diversas fases. No nosso entendimento, o letramento digital apresenta-se como um fenômeno heterogêneo, pois: 
a) Possui natureza desigual ou diferença de estrutura, já que está condicionado a fatores como: prática de leitura e escrita, contexto socioeconômico e cultural. Assim, mesmo que vivamos hoje numa sociedade bastante industrializada e tecnologizada, ainda há comunidades que carecem desse contexto $^{12}$. Nelas, os sujeitos não apresentam meios para participar de novos eventos de letramento.

b) Constitui-se por elementos variados, de diferentes naturezas, já que podemos observar sujeitos que não sabem ler ou escrever, mas que interagem bem com o mundo digital.

Os novos eventos de letramentos contam com o desenvolvimento de habilidades que não estão exclusivamente ligadas à leitura ou escritura do sistema alfabético. Os ambientes hipermidiáticos contam, em grande medida, com a linguagem icônica e solicitam aos usuários este tipo de habilidade para a navegação.

É o caso de crianças, como as deste estudo, que antes mesmo de aprenderem a ler e a escrever, podem acessar a internet por meio de links. Sem o auxílio da leitura verbal, mas contando com o conhecimento do ícone responsável para o acesso à rede, elas conseguem, utilizando o mouse, acessar a internet.

c) Não é uniforme, visto que pode se desenvolver dinamicamente para cada sujeito de acordo com outros conhecimentos e habilidades.

Diferentemente da leitura do sistema alfabético, a leitura e comportamento no ambiente digital não seguem fundamentalmente o princípio da linearidade. Cada usuário pode seguir uma rota de navegação de acordo com sua criatividade, experimentação, tentativas, sucessos e frustrações.

Aqueles sujeitos que já dominam o sistema alfabético e alguns princípios de navegação na rede estarão mais aptos a se arriscarem no ambiente digital, pois conhecem os caminhos por onde navegar. Esses sujeitos, por já possuírem uma habilidade de ler e escrever, conseguem usufruir e praticar mais ações no mundo digital que envolvem o conhecimento conquistado.

d) Pode ser formado por diversas fases, pois abarca níveis de habilidades, graus de letramento digital.

12 Não nos referimos aqui a comunidades ágrafas, mas a comunidades carentes socioeconomicamente, que convivem em meio à tecnologia, mas não possuem acesso a esse desenvolvimento por questões tanto de localização geográfica, quanto de infraestrutura, como carência de redes de energia elétrica ou telefonia. 
A perspectiva dos multiletramentos incorporada aqui revela-se não como um produto final acabado, mas pelas várias facetas que despontam na medida em que se constrói o fenômeno, ou seja, em seus graus de desenvolvimento.

Um rizoma também se norteia pela multiplicidade, pois não pode ser reduzido à unidade. $\mathrm{O}$ fenômeno do letramento digital também se apresenta como múltiplo, não deve ser entendido apenas como ler e/ou escrever na rede ou utilizando um computador, mas como uma multiplicidade de fatores que contribuem para o desenho dos vários eventos que constituem o fenômeno.

Nesse sentido, entendemos o letramento digital como um fenômeno que se constitui por fases ou graus, que se entrelaçam num desenvolvimento não-linear para a construção dos conhecimentos necessários utilizados em práticas sociais situadas. Assim, podemos construir conhecimentos práticos sobre como ligar e desligar o computador, mas ainda não sabemos utilizar um correio eletrônico. $\mathrm{Ou}$, podemos saber manejar o correio eletrônico por meio de um smartphone, mas não sabemos configurá-lo no computador.

São várias facetas do letramento digital, são vários saberes envolvidos em graus mais simples ou mais complexos. Todavia, são saberes necessários nas práticas sociais para ir ao um banco, para se inscrever num concurso, para se conectar com as pessoas que estão em lugares distantes, para saber mais informações além dos jornais e revistas da televisão ou mídia impressa, entre tantos outros exemplos.

O princípio da multiplicidade se casa com o próximo, que é o da ruptura, já que um rizoma, mesmo que rompido, quebrado, é retomado por uma de suas linhas, revelando o mapa que ele realmente é. Esse mapa é inacabado, constitui-se sempre num devir, pois sua cartografia pode ser redesenhada a qualquer instante.

O que nos leva ao quinto princípio, o da cartografia, que mostra que o rizoma tem entradas múltiplas. Um rizoma pode ser acessado por seus diferentes pontos, levando a qualquer parte do seu território. Seguindo a metáfora do mapa, o fenômeno do letramento digital também possui regiões ainda não desbravadas, de exploração e de descoberta, sendo um fenômeno novo, que ainda conta com certo grau de imprecisão teórica.

Por fim, o rizoma é ainda guiado pelo princípio de decalque, o que nos mostra que não há como pensá-lo de forma estruturalista ou num eixo genético, já que sua organização foge totalmente à metáfora da árvore, na qual se a raiz é cortada, todos os galhos morrem.

Assim como o rizoma, que se opõe ao "grafismo, ao desenho ou à fotografia, oposto aos decalques, (...) se refere a um mapa que deve ser produzido, construído, sempre desmontável, conectável, reversível, modificável, com múltiplas entradas e 
saídas, com suas linhas de fuga" (Deleuze; Guattari, 2009, p. 32-33), neste estudo, tratamos de um fenômeno, o letramento digital, ainda em construção, em processo de mapeamento teórico, pois novos saberes surgem a todo tempo e novos usos e valores também.

Como o mercado da tecnologia ganha a cada estação novos produtos, surgem com eles novos usos sociais, novas práticas e com isso, consequentemente, novos letramentos. Assim, os conceitos que podem se desenhar a partir desta conceituação e podem vir a constituir um novo pensamento. Ainda mais por se tratar de um contexto linguístico e de uma teorização sobre letramentos, é importante destacar, para finalizar, que

Num rizoma, ao contrário, cada traço não remete necessariamente a um traço linguístico: cadeias semióticas de toda natureza são aí conectadas a modos de codificação muito diversos, cadeias biológicas, políticas, econômicas, etc., colocando em jogo não somente regimes de signos diferentes, mas também estatutos de estados de coisas. (DELEUZE; GUATTARI, 2009, p. 15)

Assim, o letramento digital, entendido numa cadeia rizomática de sentidos e práticas, permite vislumbrar não um ponto fixo de desenvolvimento, mas sim a liberdade para o entrelaçamento das práticas que envolvem este fenômeno.

\section{CONSIDERAÇÕES FINAIS}

Este artigo pretendeu mostrar como o conceito de letramento digital, abrigado pela Linguística Aplicada, é complexo e multifacetado. Oriundo de um momento sócio-histórico permeado pela tecnologia, a qual configurou as novas práticas de leitura e escrita, o letramento digital recebeu em seu processo de construção como um conceito as definições profundamente conectadas às habilidades técnicas de se utilizar um computador, incorporando, posteriormente, outros modos de ser e agir no mundo, como afirma Xavier (2011), ao descrevê-lo como parte do novo modus vivendi digitale.

É inegável como o termo letramento digital está profundamente imbricado às habilidades técnicas para se usar um computador, por exemplo. Todavia, este artigo pretendeu relacionar e definir essas práticas semióticas multimodais realizadas por meio de dispositivos digitais não apenas como técnicas e habilidades, pois isso não satisfaz as demandas da sociedade da informação na pós-modernidade, e não recobre a multiplicidade de práticas sociais inseridas por esse letramento. 
Compreendemos que o entendimento sobre o letramento digital pode ser ampliado pela teoria do rizoma. O fenômeno é complexo, muitas vezes utilizado no plural como letramentos digitais, evidenciando sua amplitude, significações e vinculações às práticas sociais e culturais diversificadas. A perspectiva do letramento digital como um rizoma permite, por seus princípios, que as práticas digitais dos sujeitos aprendizes se interconectem, se desenvolvam, se ampliem, se transformem em outras, em um continuum que revele o seu maior ou menor desenvolvimento, em determinados momentos de interação contínuos. Assim, as práticas sociais e linguísticas envolvidas no letramento digital entrelaçam-se umas às outras, como um rizoma. Uma vez acrescentada uma nova prática, esta já se conecta a outras anteriores e se amplia, habilitando ininterruptamente seres digitais para enfrentarem os desafios do mundo pós-moderno.

Esperamos que a discussão aqui apresentada possa ser incorporada nas práticas educacionais que se dedicam a construir e ampliar os letramentos digitais de sujeitos aprendizes, de maneira que tais práticas empoderem os estudantes para um agir competente e autônomo na contemporaneidade.

\section{REFERÊNCIAS BIBLIOGRÁFICAS}

BARTON, D. (1994). Literacy: an introduction to the ecology of written language. Oxford: Blackwell, 2007.

BAWDEN, David. (2008). Origins and concepts of digital literacy. In: LANKSHEAR,

C.; KNOBEL, M. Digital Literacies: concepts, policies and practices. New York: Peter Lang Publishing, pp. 17-32.

BAZERMAN, C. (2007). Escrita, gênero e interação social. São Paulo: Editora Cortez.

BENJAMIN, W. (1985). Obras escolbidas: Magia e técnica, arte e política ( $7^{\mathrm{a}}$ ed.). São Paulo: Brasiliense, 1994.

BUZATO, M. (2010). Novos letramentos e apropriação tecnológica: conciliando heterogeneidade, cidadania e inovação em rede. In: RIBEIRO, Ana Elisa (Org.). Linguagem, tecnologia e educação. São Paulo: Petrópolis, pp. 41-53.

BUZATO, M. (2006). Letramentos Digitais e Formação de Professores. III Congresso IberoAmericano EducaRede, pp. 81-86.

CHARTIER, R. (1999). A aventura do livro: do leitor ao navegador. São Paulo: Editora UNESP.

COSCARELLI, C. V.; RIBEIRO, A. E. (orgs.). Letramento digital: aspectos sociais e possibilidades pedagógicas. 2. ed. Belo Horizonte: Ceale; Autêntica. 
DELEUZE, G.; GUATTARI, F. (1995). Mil Platôs - Capitalismo e Esquizofrenia. Vol. 1. Rio de Janeiro: Ed. 34, 2009.

DUPUY, J. (1995). Nas origens das Ciências Cognitivas. Tradução Roberto Leal Ferreira. São Paulo, UNESP.

ESHET-ALKALAI, Y. (2004). Digital literacy: A conceptual framework for survival skills in the digital era. Journal of Educational Multimedia and Hypermedia, 13 (1), pp. 93-106.

FRADE, I. C. A. S. (2007). Alfabetização digital: problematização do conceito e possíveis relações com a pedagogia e com a aprendizagem inicial do sistema de escrita. In: COSCARELLI, C. V.; RIBEIRO, A. E. (orgs.). Letramento digital: aspectos sociais e possibilidades pedagógicas. 2. ed. Belo Horizonte: Ceale; Autêntica, 2007, pp. 29 83.

GEE, J., HULL, G. e LANKSHEAR, C. The New Work Order. Sydney: Allen and Unwin, 1996.

GIBSON, W. (1991). Neuromancer. São Paulo: Editora Aleph.

GLISTER, P. (1997). Digital Literacy. New York: John Wiley \& Sons.

GOÉS, M. das G. T. de A. (2007). Ficção científica, cibercultura e pós-modernidade: Velocidade e religião no discurso cinematográfico de David Cronenberg - Videodrome e eXistenZ. Dissertação (Mestrado em Comunicação e Semiótica) - Programa de Estudos Pós-Graduados em Comunicação e Semiótica, Pontifícia Universidade Católica de São Paulo, São Paulo.

GOODY, J.; WATT, I. (1963). As consequências do letramento. São Paulo: Editora Paulistana, 2006.

HASAN, R. Literacy, everyday talk and society. (1996). In: Literacy in Society. London and New York: Longman, pp. 377-424.

KATO, M. A. (1986). No mundo da escrita: uma perspectiva psicolinguística. São Paulo: Ática. KNOBEL, M. \& LANKSHEAR, C. (orgs.) (2007). A new literacies sampler. New York: Peter Lang.

LANKSHEAR, C. (1997). Changing Literacies. Buckingham \& Philadelphia: Open University Press.

LANKSHEAR, C.; KNOBEL, M. (1998). Critical Literacy and New Technologies. Symposium paper, American Educational Research Association Annual Conference. San Diego, pp. 13-17. Disponível em: http://www.geocities.com/c.lankshear/critlitnewtechs. html. Acesso em: 16 jan. 2010.

LANKSHEAR, C.; KNOBEL, M. (2008). Digital Literacies: concepts, policies and practices. New York: Peter Lang Publishing.

LEMOS, A.; CUNHA, P. (orgs). (2003). Olhares sobre a Cibercultura. Porto Alegre: Sulina.

LÉVY, Pierre. (1999). Cibercultura. São Paulo: Editora 34.

LYOTARD, J. (2010). A condição pós-moderna. Rio de Janeiro: Ed. José Olympio, 2010.

MARCUSCHI, L. A; XAVIER, A. C. Hipertexto e gêneros digitais: novas formas de construção de sentido. São Paulo: Cortez, 2010. 
PARENTE, A. (1999). O Virtual e o Hipertextual. Rio de Janeiro: Pazulin.

SANTAELLA, L. (2004). Navegar no ciberespaço. O perfil cognitivo do leitor imersivo. São Paulo, Paulus.

SNYDER, Ilana. (1997). Page to screen: Taking Literacy into the Electronic Era. St Leonards: Allen \& Unwin.

SOARES, M. (2002). Novas práticas de leitura e escrita: letramento na cibercultura. Educação e Sociedade. Campinas, pp. 143-160. Disponível em: < http://www.cedes. unicamp.br>. Acesso em: 20 abr. 2009.

SOARES, M. (1998). Letramento - um tema em três gêneros. Belo Horizonte: Autêntica, 2003.

SOUZA, V. V. S. (2007). Letramento digital e formação de professores. Revista Língua Escrita, n. 2, pp. 55-69.

STREET, B. (1984). Literacy in theory and practice. Cambridge: Cambridge University Press, 1999.

VEEN, W; VRAKKING, B. (2009). Homo Zappiens - Educando na Era Digital. Porto Alegre: Artes Médicas.

WARD, D.; KARET, J. (1996). The Content-Based Approach to Internet Literacy. Disponível em: http://dwardmac.pitzer.edu/dward/c-binternetlit.html. Acesso em: 10 out. 2011.

XAVIER, A. C. (2011). Letramento digital: impactos das tecnologias na aprendizagem da Geração Y. Revista Calidoscópio. vol. 9, n. 1, pp. 3-14.

XAVIER, A. C. (2007). As Tecnologias e a aprendizagem (re)construcionista no Século XXI. Revista Hipertextus. v. 1, pp. 1-9. Disponível em: http://www.hipertextus.net/ volume1/artigoxavier.pdf. Acesso em: 24 mai. 2009.

Recebido: 20/12/2015

Aceito: 22/09/2016 